\title{
Piceatannol suppresses proliferation and induces apoptosis by regulation of the microRNA-21/phosphatase and tensin homolog/protein kinase B signaling pathway in osteosarcoma cells
}

\author{
MINGYUE ZHENG and YAOCHI WU \\ Department of Acu-mox and Tuina, The Sixth People's Hospital Affiliated to \\ Shanghai Jiao Tong University, Shanghai 200233, P.R. China
}

Received October 23, 2017; Accepted August 22, 2019

DOI: $10.3892 / \mathrm{mmr} .2020 .11484$

\begin{abstract}
Piceatannol (Pice), a natural analog of resveratrol, has been identified as an anticancer agent in various cancers by modulating the expression of microRNAs (miRNAs/miRs). However, the molecular mechanisms underlying the anticancer effects of Pice in osteosarcoma (OS) cells remain unclear. Thus, we hypothesized that Pice exerts anticancer effects on OS cells via the regulation of miRNA expression. Herein, we performed a MTT assay and flow cytometric analysis to determine cell viability and apoptosis in OS cells treated with Pice, respectively. Our results showed that Pice inhibits proliferation in a dose-dependent manner induces the apoptosis of OS cells. More importantly, miRNA microarray analysis identified that Pice alters miRNA expression profiles in human OS cells after treatment with Pice, and miR-21 was the most significantly downregulated. In addition, the therapeutic effects of Pice on OS cells were weakened by restoration of miR-21. In addition, we further verified that phosphatase and tensin homolog (PTEN), a tumor suppressor gene, is the functional target of miR-21 and Pice blocks the PTEN/AKT signaling pathway through inhibiting miR-21 expression in OS cells. Our findings suggested that Pice may exert anticancer effects on OS cells via mediating the miR-21/PTEN/AKT signaling pathway and could be considered to be a potential anticancer agent for treating OS.
\end{abstract}

Correspondence to: Professor Mingyue Zheng or Professor Yaochi Wu, Department of Acu-mox and Tuina, The Sixth People's Hospital Affiliated to Shanghai Jiao Tong University, 600 Yishan Road, Xuhui, Shanghai 200233, P.R. China

E-mail: 18930177222@163.com

E-mail: wuyaochiyc@163.com

Key words: piceatannol, anticancer agent, osteosarcoma, microRNAs, microRNA-21/phosphatase and tensin homolog/protein kinase $\mathrm{B}$ signaling pathway

\section{Introduction}

Osteosarcoma (OS), also known as osteogenic sarcoma, is the most common primary malignant bone tumor with a high potential for lung metastasis, and is commonly formed in the bones of arms and legs of children and adolescents $(1,2)$. Recently, the continuous improvement of technologies employed for auxiliary examination and treatment have increased the 5-year survival rate of OS from 20 to $70 \%$ in the past 30 years, especially the use of novel chemotherapy agents $(3,4)$. However, currently approved agents can cause notable side effects $(5,6)$. Therefore, it is urgent to develop a novel agent with high efficiency and low toxicity in the treatment of OS.

Piceatannol (3,3',4,5'-tetrahydroxy-trans-stilbene; Pice), a phenolic compound and an analog of resveratrol, first isolated from the seeds Euphorbia lagascae (7), and naturally occurs in various sources, including red wine, grapes, sugar cane, peanuts and rhubarb (8-10). Previous studies reported that Pice possesses a variety of pharmacological properties involved in anti-inflammatory $(11,12)$ and immunosuppressive features, and is a promising chemopreventive agent with anticancer activity against different types of tumors (12). it is well documented that Pice could suppress proliferation, migration, and metastasis in a variety of cancers, including breast, prostate and bladder cancer (13-15). However, the therapeutic effects and molecular mechanism of Pice in OS cells remains unclear.

MicroRNAs (miRNAs/miRs) are a class of small non-coding RNAs (21-23 nucleotides), which negatively regulate gene expression at the post-transcription level through inhibiting translation or inducing RNA degradation $(16,17)$. Many miRNAs have been identified in mammals, and some of them are expressed in a tissue-specific and developmental stage specific manner (18). It is well reported that some miRNAs have been identified to function as oncogenes or tumor suppressor genes in cancers, and could inhibit cell signaling pathways to mediate various biological processes, such as cell differentiation, apoptosis, proliferation and migration $(19,20)$. Increasing evidence revealed that natural-derived agents exert anticancer properties in various cancers via mediating the expression of miRNAs (21-23). A previous study demonstrated that Pice induces apoptosis in colorectal cancer cell lines via 
upregulation of miR-129 (24). Based on this, we speculated that Pice may suppress the growth of human OS cells through modulating miRNA expression.

In this study, we aimed to investigate the therapeutic effects of Pice on OS cells and explored the underlying molecular mechanism by examining Pice-induced changes of miRNA expression profiles. Our findings suggested that Pice may exert anticancer effects on OS cells through mediating the miR-21/PTEN/AKT signaling pathway and act as a potential chemopreventive agent for the treatment of OS.

\section{Materials and methods}

Cell culture and treatments. The human OS cell lines MG-63 and Saos-2 were obtained from the American Type Culture Collection, and cultured in RPMI-1640 medium (Invitrogen; Thermo Fisher Scientific, Inc.) supplemented with $10 \%$ fetal bovine serum (FBS; Sigma-Aldrich; Merck KGaA), $100 \mathrm{IU} / \mathrm{ml}$ penicillin, and $100 \mathrm{mg} / \mathrm{ml}$ streptomycin, at $37^{\circ} \mathrm{C}$ in a humidified atmosphere containing $5 \% \mathrm{CO}_{2}$. The cells treated with different concentrations $(0,10,25,50,100$ and $200 \mu \mathrm{M})$ at $37^{\circ} \mathrm{C}$ of Pice (Sigma-Aldrich; Merck KGaA) for $24 \mathrm{~h}$ and then the cells were collected for further measurements.

MTT assay. The antiproliferative effects of Pice against OS cells was measured using an MTT assay. Briefly, the cells $\left(1 \times 10^{4}\right)$ were seeded into 96 -well plate overnight at $37^{\circ} \mathrm{C}$, and then the cells were treated with or without $10-200 \mu \mathrm{M}$ of Pice. At $24 \mathrm{~h}$ following Pice treatment, the cells were washed with PBS and recovered in fresh medium. After incubation for $48 \mathrm{~h}$ at $37^{\circ} \mathrm{C}, 20 \mu \mathrm{l}$ of MTT solution (Sigma-Aldrich; Merck $\mathrm{KGaA}$ ) was added to each well, the concentration of MTT was $0.5 \mathrm{~g} / \mathrm{ml}$. The cells were incubated for $4 \mathrm{~h}$ at $37^{\circ} \mathrm{C}$ subsequently. The absorbance of the samples was read at $490 \mathrm{~nm}$ (Sunrise $^{\mathrm{TM}}$; Tecan Group Ltd.). Each experiment was performed in triplicate and the data were presented as mean \pm standard deviation.

Apoptosis analysis by flow cytometry. MG-63 or Saos-2 cells $\left(1 \times 10^{6}\right)$ were harvested after treatment with Pice, washed in ice-cold PBS, and fixed in 70\% ice-cold ethanol in PBS for $30 \mathrm{~min}$ at $4^{\circ} \mathrm{C}$. Then, the cells were harvested and were double stained with $5 \mu \mathrm{l}$ Annexin V-fluorescein isothiocyanate and $1 \mu \mathrm{l}$ of propidium iodide for $30 \mathrm{~min}$ at $4^{\circ} \mathrm{C}$. The stained cells were analyzed with EPICS XL-MCL FACScan (Becton Dickinson). The MultiCycle Software for Windows (version 3.11; Phoenix Flow Systems) was used to analyze the experimental data.

miRNA microarray analysis. Total RNAs were isolated from OS cells treated with Pice $(100 \mu \mathrm{M})$ using TRIzol ${ }^{\circledR}$ (Thermo Fisher Scientific, Inc.) according to manufacturer's instructions. The quantity and integrity of RNA samples was evaluated using a 2100 Bioanalyzer (Agilent Technologies, Inc.). The miRNA ULS ${ }^{\mathrm{TM}}$ Labeling Kit (Kreatech Diagnostics; Leica Biosystems) was used to label the total RNA ( $2.5 \mu \mathrm{g})$ according to the manufacturer's protocols. Labeled miRNA targets were hybridized with OneArray ${ }^{\circledR}$ Hybridization System. Microarray images were obtained using the Axon GenePix 4000B microarray scanner (Axon Instruments). Then, the scanning images imported into the GenePix Pro6.0 program (Axon Instruments) for grid alignment and data extraction. The miRNAs with intensities $\geq 50$ were used to calculate a normalization factor in all samples. Normalization was performed using median normalization. The miRNA expression profiles were determined using MEV software (version 4.6; TIGR, Microarray Software Suite 4).

Reverse transcription-quantitative polymerase chain reaction $(R T-q P C R)$. After treatment with Pice, total RNA was extracted from cultured cells using TRIzol according to the manufacturer's protocol. cDNA was synthesized using the High Capacity cDNA Synthesis Kit (Applied Biosystems; Thermo Fisher Scientific, Inc.) with miRNA-specific primers. The miR-21 primer was obtained from Guangzhou Ribobio Co., Ltd. The miR-21 primer sequences were as follows: stem-loop RT primer: 5'-GTCGTATCCAGTGCAGGGTCCGAGGTA TTCGCACTGGATACGACTCAACA-3'; forward 5'-GCCCG CTAGCTTATCAGACTGATG-3' and reverse 5'-GTGCAGG GTCCGAGGT-3'. Expression of U6 RNA served to normalize the expression of miR-21. The U6 primer sequences were as follows: forward 5'- CTCGCTTCGGCAG CACA-3' and reverse 5'-AACGCTTCACGAATTTGCGT-3'. qPCR was performed by an Applied Biosystems 7500 Real-Time PCR machine with miRNA-specific primer by TaqMan Gene Expression Assay (Applied Biosystems; Thermo Fisher Scientific, Inc.). Thermocycling conditions were: $95^{\circ} \mathrm{C}$ for $5 \mathrm{~min}$, followed by 40 cycles of $95^{\circ} \mathrm{C}$ for $30 \mathrm{sec}$ and $55^{\circ} \mathrm{C}$ for $25 \mathrm{sec}$, and extension at $72^{\circ} \mathrm{C}$ for $10 \mathrm{sec}$. All reactions were performed in triplicate. The miRNAs relative expression was analyzed with the $2^{-\Delta \Delta C q}$ method (25).

Transfection. MG-63 or Saos- 2 cells $\left(5 \times 10^{3}\right)$ cells were seeded into each well of 6-well plate, cultured in the RPMI-1640 medium containing 10\% FBS, and treated with or without Pice. Then, the cells were transfected with miR-21 mimics (5'-UAGCUUAUCAGACUGAUGUUGA-3), miR-21 inhibitor (5'-UCAACAUCAGUCUGAUAAGCUA-3') or mimics negative control (NC, 5'-UUCUCCGAACGUGUCACGUTT-3') inhibitor negative control (NC, 5'-CAGUACUUUUGUGUA GUACAA-3'), synthesized by Guangzhou Ribobio Co., Ltd., at a final concentration of $50 \mu \mathrm{M}$ using Lipofectamine ${ }^{\circledR} 2000$ reagent (Invitrogen; Thermo Fisher Scientific, Inc.) according to the manufacturer's protocol. At $48 \mathrm{~h}$ after transfection, the cells were harvested and proliferation, apoptosis and caspase-3 activity were evaluated by MTT assay, flow cytometry and colorimetric activity analysis, respectively. Target gene analyses of miR-21. A bioinformatics method was used to predict the potential target genes of miR-21. Web-based software of TargetScan 7.0 (targetscan.org/) and miRanda (microrna.org/) databases were used to predict the targets of miR-21.

Caspase-3 activity. Caspase-3 activity was determined using a colorimetric activity assay kit according to manufacturer's instructions (Bio Vison). After treatment with Pice $(100 \mu \mathrm{M})$ for $24 \mathrm{~h}$, OS cells were harvested by centrifugation at $1,000 \mathrm{xg}$ for $10 \mathrm{~min}$ at $4^{\circ} \mathrm{C}$ and incubated in lysis buffer (cat. no. P0013K; Beyotime Institute of Biotechnology) on ice for $15 \mathrm{~min}$ at RT. Then, the lysate was centrifuged at $13,000 \times \mathrm{g}$ and $4^{\circ} \mathrm{C}$ for $15 \mathrm{~min}$, the protein concentration was measured using a BCA Protein Assay Kit (Beyotime Institute of Biotechnology) according to the manufacturer's instructions. The lysates 

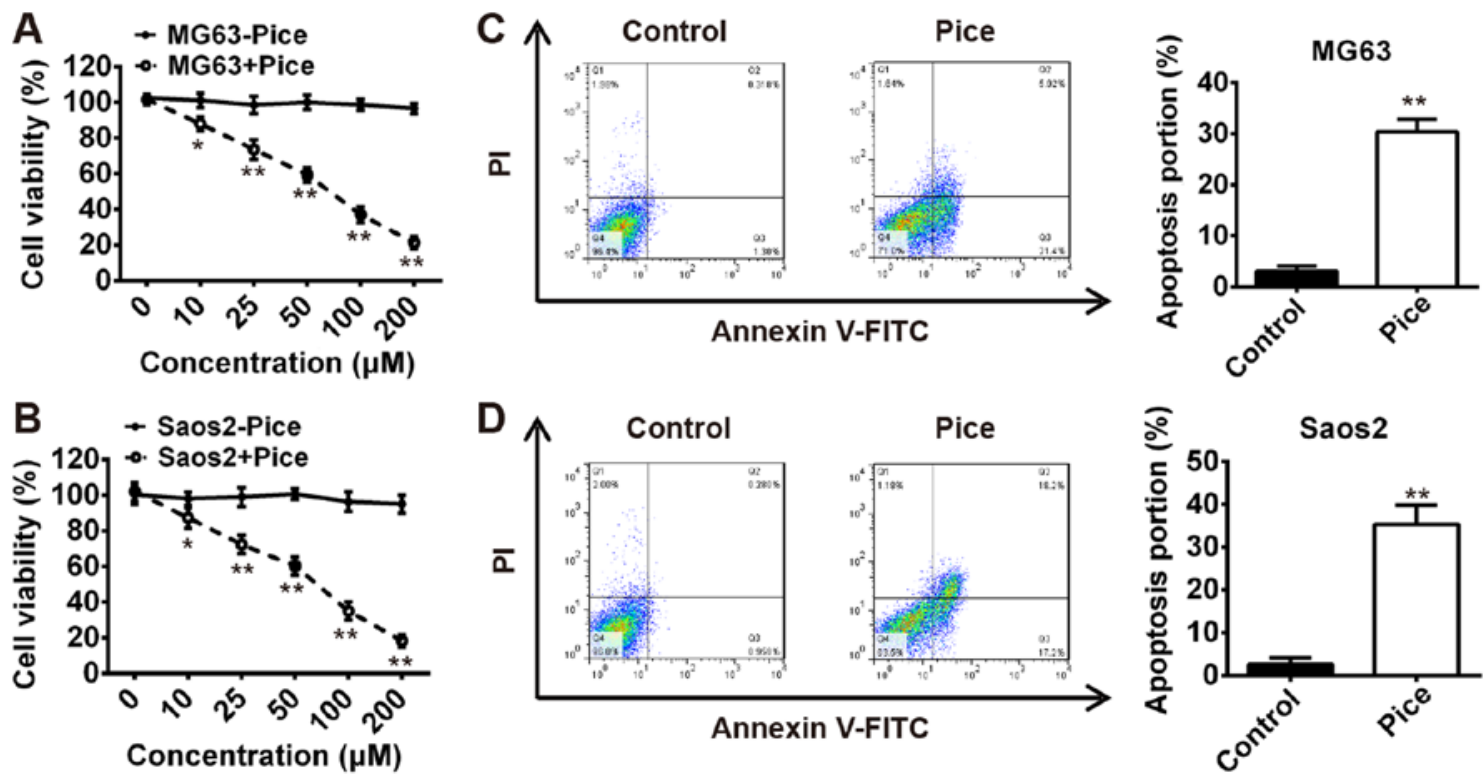

Figure 1. Pice suppresses osteosarcoma cell growth. (A and B) The MG-63 and Saos-2 cells were treated with Pice at different concentrations (10-200 $\mu$ M) for $24 \mathrm{~h}$, and then an MTT assay was used to measure cell viability. (C and D) Flow cytometric analysis was performed to determine the number of apoptotic MG-63 and Saos-2 cells treated with Pice $(100 \mu \mathrm{M})$ for $24 \mathrm{~h}$. Data were presented as the mean \pm standard deviation of three individual experiments. ${ }^{*}<0.05$, ${ }^{* * *} \mathrm{P}<0.01$ vs. control. FITC, fluorescein isothiocyanate; PI, propidium iodide; Pice, Piceatannol.

(10 $\mu \mathrm{l})$ were incubated with $10 \mu \mathrm{l}$ of $0.2 \mathrm{mM}$ Ac-DEVD-pNA in $80 \mu \mathrm{l}$ of reaction buffer at $37^{\circ} \mathrm{C}$ for $2 \mathrm{~h}$. The samples were measured with a microplate reader (Model 680, Bio-Rad Laboratories, Inc.) at an absorbance of $405 \mathrm{~nm}$.

Luciferase reporter assay. The human phosphatase and tensin homolog (PTEN) 3'-untranslated region (3'-UTR) containing complementary sequences for the seed sequence of miR-21 was amplified by PCR and cloned into the firefly luciferase expressing vector pMIR-REPORT (Ambion; Thermo Fisher Scientific, Inc.; wild-type pMIR-REPORT-PTEN-3'-UTR, wt). A mutant of the 3'-UTR with a mutation (mut) of complementary sequences for the seed sequence of miR-21 (pMIR-REPORT-PTEN-mut-3'-UTR) was performed using the QuikChange II Site-Directed Mutagenesis Kit (Stratagene; Agilent Technologies, Inc.). The MG-63 cells were seeded into 24-well plate and transfected with wt or mut reporter vector, together with miR-21 mimics or miR-21 inhibitor using Lipofectamine ${ }^{\circledR} 2000$. The pRL-TK plasmid (Promega Corporation) was used as a normalizing control. At $48 \mathrm{~h}$ after transfection, the luciferase activity was determined with the Dual-Light luminescent reporter gene assay system (Applied Biosystems; Thermo Fisher Scientific, Inc.), and the relative firefly luciferase activity was normalized with Renilla luciferase. Each determination was performed in triplicate.

Western blot analysis. After $48 \mathrm{~h}$ following transfection, total protein from cells was isolated using radioimmunoprecipitation assay buffer with protease inhibitor Cocktail (Pierce; Thermo Fisher Scientific, Inc.). The protein concentration was determined using a BCA protein assay kit. Total proteins $(20 \mu \mathrm{g})$ were separated via 10\% SDS-PAGE and then transferred onto to polyvinylidene difluoride membranes (BD Pharmingen; BD Biosciences). The membranes were blocked with $5 \%$ non-fat milk at $4^{\circ} \mathrm{C}$ overnight, and incubated with primary antibodies against PTEN (cat. no. sc-7974, 1:1,000, Santa Cruz Biotechnology, Inc.), phosphorylated (p)-AKT (cat. no. sc-7985-R, 1:1,000, Santa Cruz Biotechnology, Inc.) and AKT (cat. no. sc-5298, 1:1,000, Santa Cruz Biotechnology, Inc.) at $4^{\circ} \mathrm{C}$ overnight. $\beta$-actin (cat. no. A-5441, 1:1,000, Sigma-Aldrich; Merck KGaA) served as an internal control. Horseradish peroxidase-conjugated (cat. no. sc-2031, 1:5,000, Santa Cruz Biotechnology, Inc.) antibodies were used as the secondary antibodies, incubating with the secondary antibody for $1 \mathrm{~h}$ at room temperature. The protein bands were scanned on the using the ChemiDocXRS + Imaging System (Bio-Rad Laboratories, Inc.). The band intensity was quantified using Quantity One v4.6.2 software (Bio-Rad Laboratories, Inc.). All the experiments were performed in triplicate.

Statistical analysis. The SPSS 14.0 software (SPSS, Inc.) was used to analyze the data. Numerical data presented as the mean \pm standard deviation. The difference between two groups was analyzed with a Student's t-test. Multiple groups were compared using one-way analysis of variance with Tukey's post hoc tests. $\mathrm{P}<0.05$ was considered to indicate a statistically significant difference and $\mathrm{P}<0.01$ indicated a highly statistically significant difference.

\section{Results}

Pice suppresses OS cell growth. To examine the effects of Pice on the growth of OS cells, MG-63 or Saos-2 cells were treated with Pice at different concentrations $(10-200 \mu \mathrm{M})$ for $24 \mathrm{~h}$, and then the cell viability was measured using an MTT assay. Our results demonstrated that treatment with $10-200 \mu \mathrm{M}$ Pice significantly inhibited Saos-2 and MG-63 cell proliferation in a dose-dependent manner compared with the control $(\mathrm{P}<0.01$; Fig. 1A and B). To explore whether the reduction in cell viability was associated with cell apoptosis, we performed 


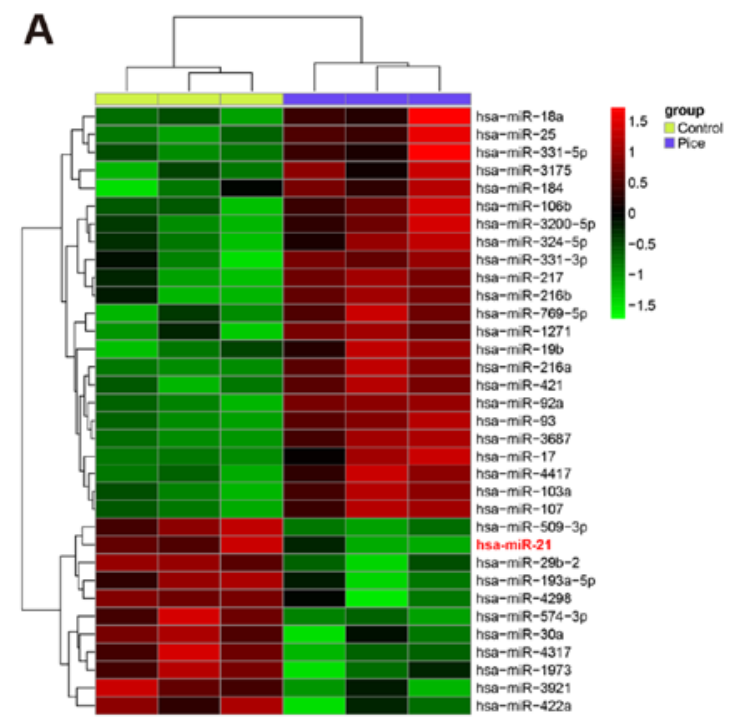

B

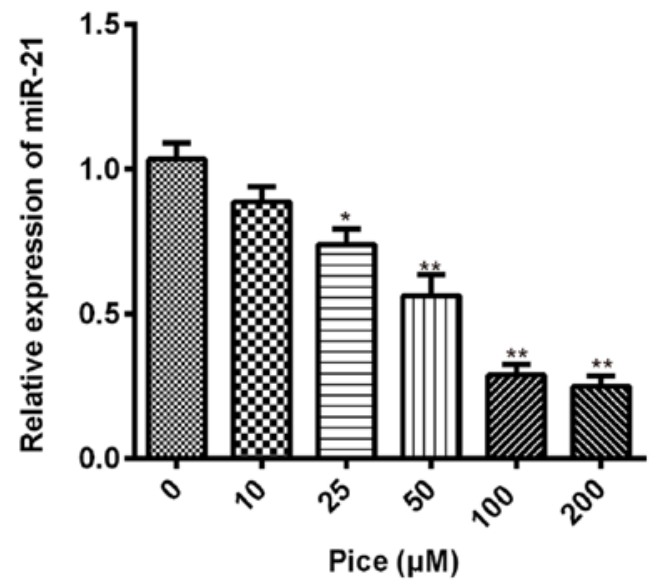

Figure 2. Expression profile of miRNA in Pice-treated osteosarcoma cells. (A) Saos-2 cells were treated with Pice (100 $\mu \mathrm{M})$ for 24 h and microarray analysis was used to determine miRNA levels. The heatmap revealed significant expressional changes of miRNAs in OS cells treated with Pice. Green represented downregulated expression and red indicated upregulation. (B) Saos-2 cells were treated with 10-200 $\mu \mathrm{M}$ of Pice for $24 \mathrm{~h}$ and reverse transcription-quantitative polymerase chain reaction was conducted to determine miR-21 expression. Data were presented as the mean \pm standard deviation of three individual experiments. ${ }^{*} \mathrm{P}<0.05,{ }^{* *} \mathrm{P}<0.01$ vs. control. miR, microRNA; Pice, Piceatannol.

flow cytometric analysis to examine apoptosis of MG-63 and Saos-2 cells treated with Pice. As presented in Fig. 1Cand D, compared with the control group, the number apoptotic cells was significantly increased for both cell lines after treatment with $100 \mu \mathrm{M}$ Pice for $24 \mathrm{~h}(\mathrm{P}<0.01)$. These data indicated that Pice may be a potential therapeutic agent in the treatment of OS.

Pice induces the aberrant expression of miRNAs in OS cells. Increasing evidence revealed that miRNAs are associated a variety of biological and pathological processes, including cellular differentiation, proliferation, apoptosis and carcinogenesis $(26,27)$. Recently, Pice has been identified to exhibit anti-cancer effects on colorectal cancer cell lines through upregulation of miR-129 (24). To investigate whether Pice possessed the suppressive effect in OS cells via modulating miRNA expression, microarray analysis was performed to measure the miRNA expression profiles in OS cells after treatment with Pice $(100 \mu \mathrm{M})$ for $24 \mathrm{~h}$. We observed that a large set of miRNAs expression were altered after Pice treatment compared with the control, and that miR-21 was the most significantly downregulated in human OS cells after Pice treatment (Fig. 2A). miR-21 has been reported to act as an oncogene in OS through promoting proliferation and invasion, and suppressing apoptosis of OS cells (28-30). Based on these studies, we further measured the miR-21 levels in OS cells treated with Pice. The Saos- 2 cells were treated with $10-200 \mu \mathrm{M}$ of Pice for $24 \mathrm{~h}$ and then the expression of miR-21 was analyzed using RT-qPCR. The results showed that Pice treatment reduced miR-21 expression in a dose-dependent manner in OS cells (Fig. 2B). These results suggested that Pice may exert anticancer effects through regulating miR-21 expression in human OS cells.

Overexpression of miR-21 attenuates the therapeutic effects of Pice. To determine whether Pice exhibits the anticancer effects on OS cells via modulating miR-21 expression, MG-63 and Saos- 2 cells were treated with or without $100 \mu \mathrm{M}$ of Pice for $24 \mathrm{~h}$ and transfected with miR-21 mimics or mimic NC, and cell viability and apoptosis were measured by an MTT assay and flow cytometric analysis, respectively. As shown in Fig. 3A and B, transfection with miR-21 mimic/inhibitor resulted in the upregulation and downregulation of miR-21 in MG63 and Saos-2 cells, respectively, compared with the NC-transfected cells $(\mathrm{P}<0.01)$. It was found that Pice treatment significantly suppressed the viability of MG-63 and Saos-2 cells compared with control, but overexpression of miR-21 significantly increased cell viability compared with the Pice-treated group $(\mathrm{P}<0.01$; Fig. $3 \mathrm{C}$ and $\mathrm{F})$. Moreover, the Pice-induced apoptosis effect was significantly impaired by overexpression of miR-21 in MG-63 and Saos-2 cells compared with Pice-treated group ( $\mathrm{P}<0.01$; Fig. 3D and $\mathrm{G})$. Additionally, it was observed that Pice significantly increased caspase-3 activity compared with control, but this enhancement was rescued by overexpression of miR-21 in MG-63 and Saos-2 cells $(\mathrm{P}<0.01$; Fig. $3 \mathrm{E}$ and $\mathrm{H})$. Taken together, these data suggested that the therapeutic effects of Pice were attenuated by overexpression of miR-21 in OS cells.

PTEN is a target of miR-21 in OS cells. It is reported that the protein PTEN has been reported to act as a functional target of miR-21 in various human cancer cells, including lung cancer, esophageal cancer and lung squamous carcinoma (31-33). However, whether PTEN is a direct target of miR-21 in OS cells remains to be elucidated. To identify the target of miR-21 in OS cells, we performed TargetScan analysis to predict the target genes of miR-21 and identified PTEN as a potential target of miR-21 (Fig. 4A). To verify this bioinformatic predication, we established the luciferase reporter plasmids containing the wt or mut 3'-UTR segments of PTEN (Fig. 4A). A luciferase reporter assay showed that miR-21 mimic significantly inhibited the luciferase activity compared with the 
A
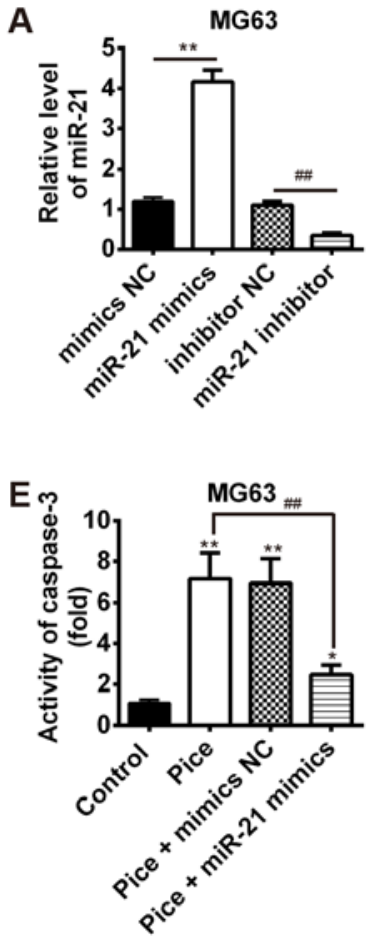

B
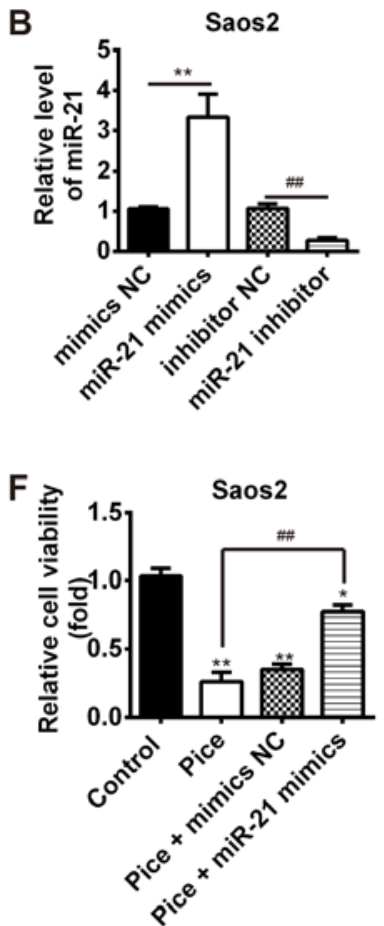

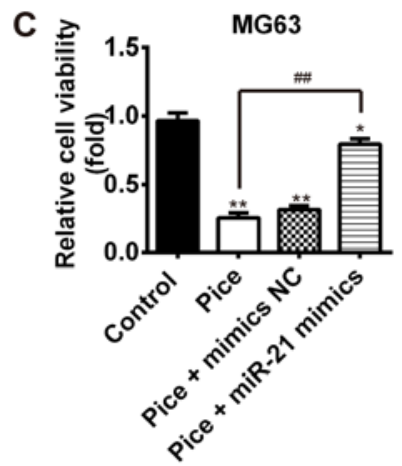

G

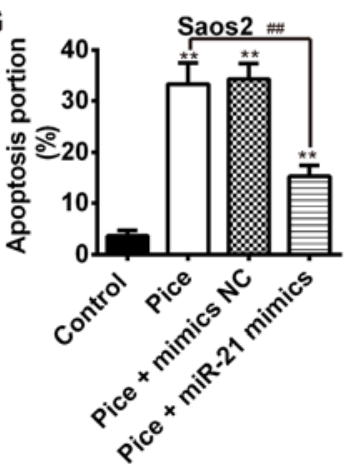

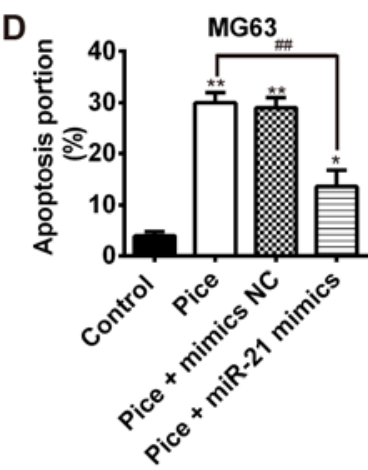

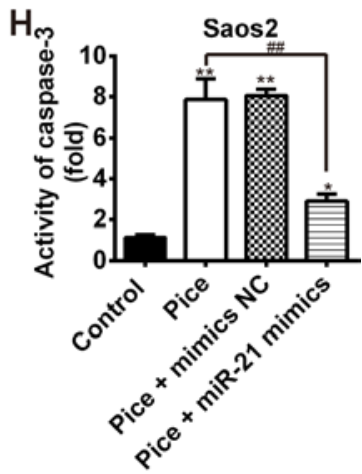

Figure 3. Overexpression of miR-21 attenuates the therapeutic effects of Pice. The MG-63 or Saos-2 cells were transfected with miR-21 mimics or mimic NC after treatment with or without $100 \mu \mathrm{M}$ of Pice for $24 \mathrm{~h}$. (A and B) MG-63 and Saos-2 cells were transfected with miR-21 mimic/inhibitor or mimic/inhibitor NC. The expression of miR-21 was measured using reverse transcription-quantitative polymerase chain reaction analysis ${ }^{(* *} \mathrm{P}<0.01$, $\left.{ }^{\# \#} \mathrm{P}<0.01\right)$. (C-E) $\mathrm{MTT}$ assay, flow cytometric analysis and colorimetric activity assay kit were employed to measure cell viability, apoptosis and caspase-3 activity in MG-63 cells, respectively. (F-H) The cell viability, apoptosis and caspase-3 activity were determined in Saos-2 cells using an MTT assay, flow cytometric analysis and colorimetric activity assay kit, respectively. Data were presented as the mean \pm standard deviation of three independent experiments. ${ }^{*} \mathrm{P}<0.05,{ }^{* *} \mathrm{P}<0.01$ vs. control. ${ }^{\#} \mathrm{P}<0.01$. miR, microRNA; NC, negative control; Pice, Piceatannol.

A

wt PTEN 3'UTR: 5' - aacuacua-uugtaAAGCUA - 3' IIIIII

hsa-miR-21: $\quad$ ' - uguagucagacuaUUCGAU - 5'

mut PTEN 3'UTR: 5' - aacuacua-uugt GCAUAG- 3'
B

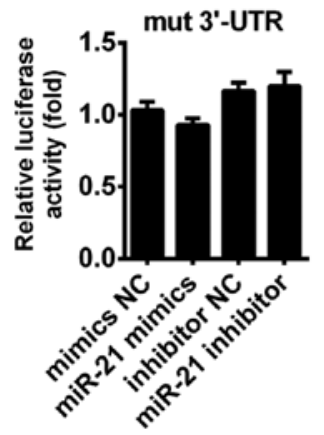

D
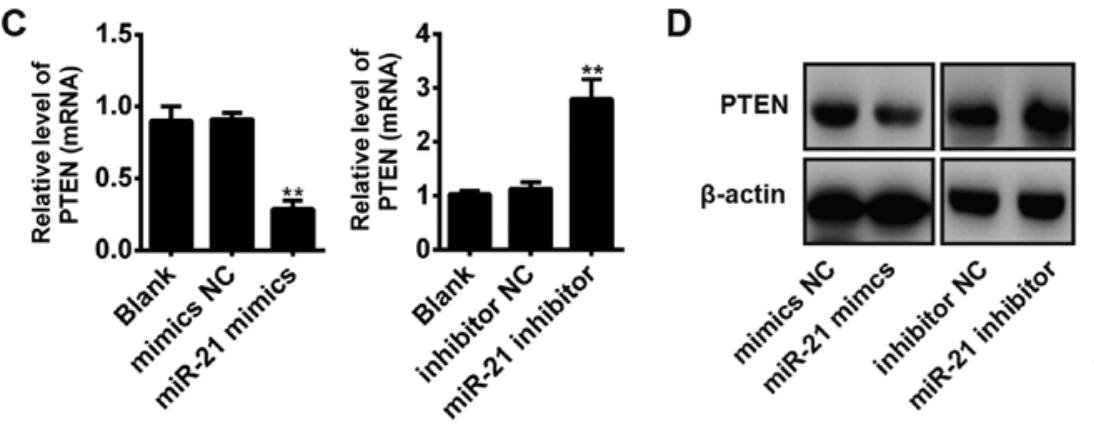
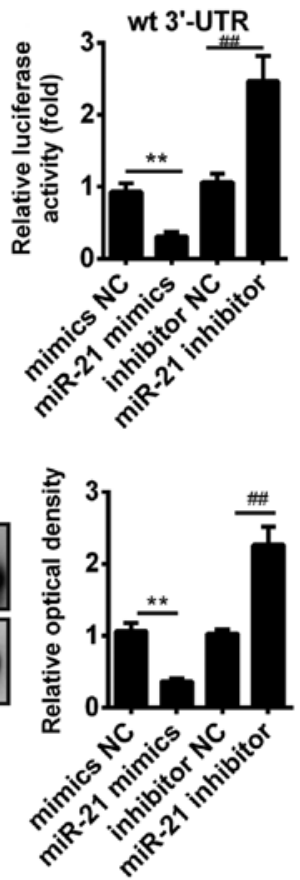

Figure 4. PTEN is a direct target of miR-21 in osteosarcoma cells. (A) The PTEN 3'-UTR region containing the wt or mut binding site for miR-21. (B) The Saos-2 cells were co-transfected with miR-21 mimics/inhibitor or NC oligos and plasmid pMIR-REPORT-PTEN-3'-UTR (wt, mut). The relative firefly luciferase activity normalized with Renilla luciferase was measured $48 \mathrm{~h}$ after transfection. ${ }^{* *} \mathrm{P}<0.01$, ${ }^{\# \#} \mathrm{P}<0.01$. (C) Saos-2 cells were transfected with miR-21 mimic/inhibitor or corresponding mimic/inhibitor NC, and reverse transcription-quantitative polymerase chain reaction was used to measure PTEN mRNA level. ${ }^{* *} \mathrm{P}<0.01$ vs. NC. (D) Western blot analysis was conducted to detect the PTEN protein level in Saos- 2 cells after transfection with miR-21 mimic/inhibitor or corresponding mimic/inhibitor $\mathrm{NC} ; \beta$-actin was used as an internal control. ${ }^{* *} \mathrm{P}<0.01,{ }^{\# \#} \mathrm{P}<0.01$. Data were presented as the mean \pm standard deviation of three individual experiments. Hsa, homo sapiens; miR, microRNA; mut, mutant; NC, negative control; PTEN, phosphatase and tensin homolog; wt, wild-type; 3'-UTR, 3'-untranslated region. 

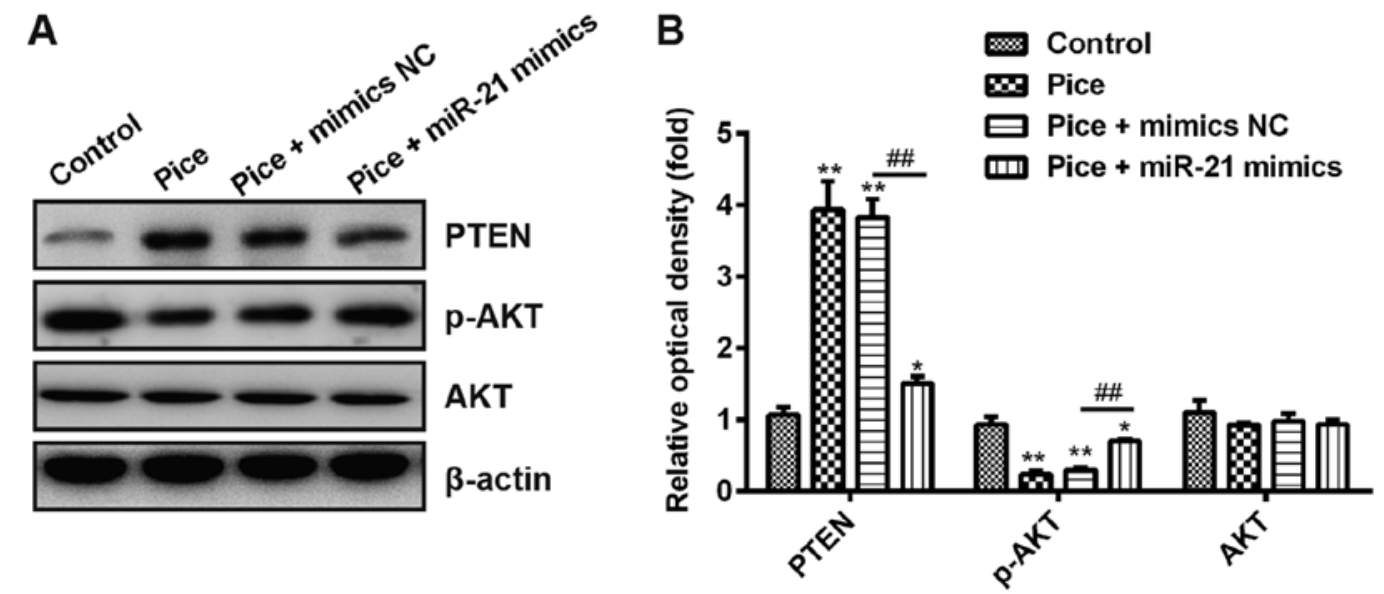

Figure 5. Pice blocks the PTEN/AKT signaling pathway via inhibiting miR-21 expression in osteosarcoma cells. (A) Saos-2 cells were transfected with miR-21 mimics/mimics NC after treatment with $100 \mu \mathrm{M}$ of Pice for $24 \mathrm{~h}$, and the expression levels of PTEN, p-AKT and AKT were measured by western blot analysis. $\beta$-actin was used as an internal control. (B) The histogram indicated the relative protein expression obtained for each group. ${ }^{*} \mathrm{P}<0.05,{ }^{* *} \mathrm{P}<0.01$ vs. control; ${ }^{\# \#} \mathrm{P}<0.01$. Data were presented as the mean \pm standard deviation of three individual experiments. AKT, protein kinase B; miR, microRNA; NC, negative control; p, phosphorylated; PTEN, phosphatase and tensin homolog.

mimic NC, but miR-21 inhibitor significantly enhanced the luciferase activity compared with the inhibitor $\mathrm{NC}(\mathrm{P}<0.01$; Fig. 4B). Additionally, miR-21 mimic or inhibitor did not affect the luciferase activity in the cells transfected with pMIR-REPORT-PTEN-mut-3'-UTR (Fig. 4B). To further confirm that the PTEN expression is regulated by miR-21, we performed the RT-qPCR and western blotting to detect PTEN mRNA and protein levels, respectively. The results showed that overexpression of miR-21 significantly inhibited the PTEN mRNA and protein levels compared with NC, but knockdown of miR-21 significantly increased the PTEN mRNA and protein levels $(\mathrm{P}<0.01$; Fig. $4 \mathrm{C}$ and $\mathrm{D})$. These results suggested that miR-21 suppresses PTEN by targeting its 3'-UTR in OS cells.

Pice blocks the PTEN/AKT signaling pathway via modulating the expression of miR-21 in OS cells. It has been reported that the PI3K/AKT signaling pathway plays a key role in cell survival, and possesses a protective effect on tumorigenesis-associated apoptosis in cancer cells (34). Moreover, AKT was negatively regulated by PTEN, which serves a key role in a variety of diseases through modulating cell proliferation, survival, apoptosis and metabolism (35). A recent study has demonstrated that miR-21 mediates the proliferation, apoptosis, migration, invasion and the cell cycle of human esophageal cancer cells, through targeting key proteins of the PTEN/PI3K/AKT signaling pathway (36). Based on this background, we hypothesized that Pice may also modulate the PTEN/AKT signaling pathway via downregulation of miR-21 in OS cells. To investigate this hypothesis, Saos- 2 cells were transfected with or without miR-21 mimics after treatment with or without Pice, and Western blot analysis was used to measure the expression of PTEN and AKT. Our results showed that Pice treatment resulted in PTEN upregulation and p-AKT downregulation compared with the control, but overexpression of miR-21 significantly reduced PTEN expression and increased p-AKT expression in Pice-treated cells after transfection with miR-21 mimics compared with transfection with mimics $\mathrm{NC}(\mathrm{P}<0.01$; Fig. 5A and $\mathrm{B})$. Collectively, our data suggested that Pice blocks the PTEN/AKT signaling pathway via inhibiting miR-21 expression in OS cells.

\section{Discussion}

Accumulating evidence revealed that Pice has been identified to act as anticancer agent in various cancers via suppressing proliferation, migration, and metastasis (13-15). However, whether Pice exerts such anti-cancer effects when used in the context of the treatment of human OS remains unclear. In present study, our results demonstrated that Pice suppresses proliferation and in a dose-dependent manner prompts apoptosis in OS cells. More importantly, we found that Pice alters miRNAs expression in human OS cells and reduces miR-21 expression, which was significantly downregulated in a dose-dependent manner. Moreover, the therapeutic effects of Pice on OS cells were attenuated by overexpression of miR-21. Additionally, we verified that PTEN is a direct target of miR-21 and Pice blocks the PTEN/AKT signaling pathway via suppressing miR-21 expression in OS cells. These data suggested that Pice may exert therapeutic effects on OS cells via modulating miR-21/ PTEN/AKT signaling pathway and function as a promising therapeutic agent in the treatment of OS.

Previous studies uncovered that resveratrol confers an anticancer effect in different cancers through repressing cell growth $(37,38)$. Increasing evidence demonstrated that Pice, a natural analog of resveratrol, induces apoptosis and cell cycle arrest in human melanoma (39). Additionally, Pice has been reported to act as an anti-tumor agent in leukemia cells $(40,41)$. In the present study, the results showed that Pice inhibits proliferation and induces apoptosis in a dose-dependent manner in both Saos-2 and MG-63 cells. These data suggested that Pice may be a potential therapeutic agent in the treatment of OS.

Mounting evidence demonstrated that miRNAs negatively regulate their target genes through inducing mRNA cleavage, translational arrest and a combination of the two, mainly by direct targeting of the 3 '-UTRs of mRNAs $(17,42,43)$. It is extensively reported that miRNAs can function as tumor suppressors or oncogenes by targeting genes involved in 
tumor cell proliferation, apoptosis, differentiation and metastasis (44). One study demonstrated that resveratrol and its analogs were used as attractive miRNA-mediated chemopreventive and therapeutic strategy in prostate cancer (45). Ke et al (46) revealed that resveratrol and Pice reduce the expression of miR-183, resulting in attenuated osteoclastogenesis. In addition, Pice has been identified to suppress colorectal cancer growth via upregulation of miR-129. Therefore, to investigate whether Pice exerts anticancer effects on OS cells via mediating miRNAs, we used microarray analysis to determine the miRNA expression profiles of OS cells after treatment with Pice. We found that Pice induces the aberrant expression of miRNAs and miR-21 was the most significantly downregulated in OS cells. Moreover, Pice decreases miR-21 in a dose-dependent manner as verified by RT-qPCR. miR-21 has been identified to act as an oncogene in OS via promoting OS cell proliferation and invasion, and suppressing apoptosis (28-30). Then, we further investigated whether the therapeutic effects of Pice were modulated by miR-21 expression; we observed that overexpression of miR-21 attenuates the therapeutic effects of Pice via promoting cell growth and inhibiting caspase-3 activity. Taken together, these results suggested that Pice harbored the anticancer effects on OS cells may suppress miR-21 expression. However, the potential molecular mechanism require further investigation.

Previously, many studies demonstrated that numerous miRNAs are upregulated or downregulated in OS, and are often associated with the entire process of tumor development $(44,47)$. The relationship between miRNA expression and the prognosis of patients with OS has been extensively reported. Cheng et al (48) conducted a meta-analysis of the prognostic significance miRNAs in OS, and indicated that a number of other miRNAs are either upregulated (miR-214, miR-29, and miR-148a) or downregulated (miR-382, miR-26a, miR-195, and miR-124) in OS. However, these miRNAs (miR-214, miR-29, miR-148a, miR-382, miR-26a, miR-195, and miR-124) were not detected in our microarray analysis; whether these miRNAs are involved in the anticancer effects of Pice on OS is yet to be determined.

Several studies have confirmed that miR-21 inhibits PTEN expression by directly targeting its 3'-UTR in a variety of cancer cells (31-33). Consistent with previous reports, our data showed that PTEN is a functional target of miR-21 in OS cells. PTEN, a tumor suppressor gene, plays an important role in many types of solid tumors through modulating cell apoptosis and the cell cycle (33), and its tumor suppressor activity is dependent on its lipid phosphatase activity, which negatively modulates the PI3K/AKT/mTOR pathway (49). Therefore, we speculated that Pice may regulate the PTEN/AKT signaling pathway via inhibiting miR-21 expression. Our results demonstrated that Pice treatment resulted in PTEN upregulation and p-AKT downregulation, but overexpression of miR-21 significantly decreased PTEN expression and increased p-AKT expression in Pice-treated OS cells. These data indicated that Pice could modulate the PTEN/AKT signaling pathway via suppressing miR-21 expression, suggesting Pice may exert anticancer effects on OS cells via modulating miR-21/PTEN/AKT signaling pathway.

Various natural products have been reported to prevent or treat tumors, due to their effects on cellular defenses or by targeting the key transcription factors, such as nuclear factor- $\kappa \mathrm{B}$, signal transducers, activator protein and activators of transcription and others (50-53). The differential effects of natural products from plants in tumor cells may be due to different abilities to induce specific apoptotic pathways, modify the levels of major metabolic enzymes, or induce detoxifying enzymes and tumor suppressor genes (54-56). Resveratrol, a polyphenol, which has been found in various plants, including grapes, passion fruit, white tea, and Japanese knotweed, displays a wide spectrum of biological activity (50). Previously, polyphenolic compounds were reported to exhibit anti-cancer effects in cancers, including green tea polyphenol, honokiol (HNK), and Pice (50). HNK is a small organic molecule purified from magnolia species and has demonstrated antitumor activities in a variety of tumor cell lines (57). HNK inhibited the growth and proliferation of oral squamous cell carcinoma cells in vitro (58). Recently, Yang et al (59) reported that HNK inhibits proliferation and induces apoptosis through modulating the miR-21/PTEN/PI3K/AKT signaling pathway in human OS cells. In the present study, our results revealed that Pice exerts anticancer effects on OS cells via regulating miR-21/ PTEN/AKT signaling pathway. These data indicated that plant-derived polyphenolic compounds may exert anticancer effects in various cancers by mediating miRNA expression. In subsequent experiments, we will further verify whether the anticancer effects of plant-derived polyphenolic compounds are associated with miRNA-mediated signaling pathways.

In conclusion, our results revealed that Pice suppressed cell proliferation in a dose-dependent manner and induces the apoptosis of OS cells. Meanwhile, we verified that Pice induces the aberrant expression of miRNAs in human OS cells, and miR-21 was the most significantly downregulated. Most importantly, the therapeutic effects of Pice on OS cells were weakened by overexpression of miR-21 via blocking the PTEN/AKT signaling pathway. Taken together, our findings indicated that the molecular mechanism underlying the observed Pice-induced apoptosis could be regulated by a miR-21/PTEN/AKT axis in human OS cells.

\section{Acknowledgements}

Not applicable.

\section{Funding}

This study was supported by the Scientific research project of Shanghai science and technology commission (grant no. 18401902400) and the three-year action plan for further accelerating the development of TCM in Shanghai (grant no. ZY(2018-2020)-FWTX-4020).

\section{Availability of data and materials}

All data generated or analyzed during this study are included in this published article.

\section{Authors' contributions}

MZ and YW performed the experiments, contributed to data analysis and wrote the paper. MZ and YW analyzed the 
data. YW made substantial contributions to the concept of the study, contributed to data analysis and acquired experimental materials. Both authors read and approved the final manuscript.

\section{Ethics approval and consent to participate}

Not applicable.

\section{Patient consent for publication}

Not applicable.

\section{Competing interests}

The authors declare that they have no competing interests.

\section{References}

1. Ottaviani G and Jaffe N: The Epidemiology of Osteosarcoma In: Pediatric and Adolescent Osteosarcoma. Jaffe N, Bruland OS and Bielack S (eds). Springer US, Boston, MA, pp3-13, 2010.

2. Wang H, Tang M, Ou L, Hou M, Feng T, Huang YE, Jin Y, Zhang $\mathrm{H}$ and Zuo G: Biological analysis of cancer specific microRNAs on function modeling in osteosarcoma. Sci Rep 7: $5382,2017$.

3. Bielack SS, Marina N, Ferrari S, Helman LJ, Smeland S, Whelan JS and Reaman GH: Osteosarcoma: The same old drugs or more? J Clin Oncol 26: 3102-3103, author reply 3104-3105, 2008.

4. Epis MR, Giles KM, Beveridge DJ, Richardson KL, Candy PA, Stuart LM, Bentel J, Cohen RJ and Leedman PJ: miR-331-3p and Aurora Kinase inhibitor II co-treatment suppresses prostate cancer tumorigenesis and progression. Oncotarget 8: 55116-55134, 2017

5. Longhi A, Errani C, De Paolis M, Mercuri M and Bacci G: Primary bone osteosarcoma in the pediatric age: State of the art Cancer Treat Rev 32: 423-436, 2006.

6. Marina N, Gebhardt M, Teot L and Gorlick R: Biology and therapeutic advances for pediatric osteosarcoma. Oncologist 9: 422-441, 2004

7. Li Z, Yang X, Dong S and Li X: DNA breakage induced by piceatannol and copper(II): Mechanism and anticancer properties. Oncol Lett 3: 1087-1094, 2012.

8. Cantos E, Espín JC, Fernández MJ, Oliva J and Tomás-Barberán FA: Postharvest UV-C-irradiated grapes as a potential source for producing stilbene-enriched red wines. J Agric Food Chem 51: 1208-1214, 2003.

9. Matsuda H, Tomohiro N, Hiraba K, Harima S, Ko S, Matsuo K, Yoshikawa $\mathrm{M}$ and Kubo M: Study on anti-Oketsu activity of rhubarb II. Anti-allergic effects of stilbene components from Rhei undulati Rhizoma (dried rhizome of Rheum undulatum cultivated in Korea). Biol Pharm Bull 24: 264-267, 2001.

10. Rimando AM, Kalt W, Magee JB, Dewey J and Ballington JR Resveratrol, pterostilbene, and piceatannol in vaccinium berries J Agric Food Chem 52: 4713-4719, 2004.

11. Kim YH, Kwon H-S, Kim DH, Cho HJ, Lee HS, Jun JG, Park JH and Kim JK: Piceatannol, a stilbene present in grapes, attenuates dextran sulfate sodium-induced colitis. Int Immunopharmacol 8 : 1695-1702, 2008.

12. Jin CY, Moon DO, Lee KJ, Kim MO, Lee JD, Choi YH, Park YM and Kim GY: Piceatannol attenuates lipopolysaccharide-induced NF-kappaB activation and NF-kappaB-related proinflammatory mediators in BV2 microglia. Pharmacol Res 54: 461-467, 2006.

13. Song NR, Hwang MK, Heo YS, Lee KW and Lee HJ: Piceatannol suppresses the metastatic potential of MCF10A human breast epithelial cells harboring mutated $\mathrm{H}$-ras by inhibiting MMP-2 expression. Int J Mol Med 32: 775-784, 2013.

14. Jayasooriya RGPT,Lee YG, Kang CH,Lee KT, Choi YH, Park SY, Hwang JK and Kim GY: Piceatannol inhibits MMP-9-dependent invasion of tumor necrosis factor- $\alpha$-stimulated DU145 cells by suppressing the Akt-mediated nuclear factor- $\kappa \mathrm{B}$ pathway. Oncol Lett 5: 341-347, 2013.
15. Kuo PL and Hsu YL: The grape and wine constituent piceatannol inhibits proliferation of human bladder cancer cells via blocking cell cycle progression and inducing Fas/membrane bound Fas ligand-mediated apoptotic pathway. Mol Nutr Food Res 52: 408-418, 2008

16. Croce CM: Causes and consequences of microRNA dysregulation in cancer. Nat Rev Genet 10: 704-714, 2009.

17. Bartel DP: MicroRNAs: Target recognition and regulatory functions. Cell 136: 215-233, 2009.

18. Zhao JJ, Yang J, Lin J, Yao N, Zhu Y, Zheng J, Xu J, Cheng JQ, Lin JY and Ma X: Identification of miRNAs associated with tumorigenesis of retinoblastoma by miRNA microarray analysis. Childs Nerv Syst 25: 13-20, 2009.

19. Zhuang LK, Xu GP, Pan XR, Lou YJ, Zou QP, Xia D, Yan WW, Zhang YT, Jia PM and Tong JH: MicroRNA-181a-mediated downregulation of AC9 protein decreases intracellular cAMP level and inhibits ATRA-induced APL cell differentiation. Cell Death Dis 5: e1161, 2014.

20. Zhang B, Pan X, Cobb GP and Anderson TA: MicroRNAs as oncogenes and tumor suppressors. Dev Biol 302: 1-12, 2007.

21. Zamani M, Sadeghizadeh M, Behmanesh M and Najafi F: Dendrosomal curcumin increases expression of the long non-coding RNA gene MEG3 via up-regulation of epi-miRs in hepatocellular cancer. Phytomedicine 22: 961-967, 2015.

22. Liu S, Fang Y, Shen H, Xu W and Li H: Berberine sensitizes ovarian cancer cells to cisplatin through miR-21/PDCD4 axis. Acta Biochim Biophys Sin (Shanghai) 45: 756-762, 2013.

23. Hong M, Wang N, Tan YH, Tsao S-W and Feng Y: MicroRNAs and Chinese Medicinal Herbs: New Possibilities in Cancer Therapy. Cancers (Basel) 7: 1643-1657, 2015.

24. Zhang H, Jia R, Wang C, Hu T and Wang F: Piceatannol promotes apoptosis via up-regulation of microRNA-129 expression in colorectal cancer cell lines. Biochem Biophys Res Commun 452: 775-781, 2014.

25. Livak KJ and Schmittgen TD: Analysis of relative gene expression data using real-time quantitative PCR and the 2(- $\Delta \Delta \mathrm{C}(\mathrm{T}))$ Method. Methods 25: 402-408, 2001.

26. Bartel DP: MicroRNAs: Genomics, biogenesis, mechanism, and function. Cell 116: 281-297, 2004.

27. le Sage $C$ and Agami R: Immense promises for tiny molecules: Uncovering miRNA functions. Cell Cycle 5: 1415-1421, 2006.

28. Ren X, Shen Y, Zheng S, Liu J and Jiang X: miR-21 predicts poor prognosis in patients with osteosarcoma. Br J Biomed Sci 73: 158-162, 2016.

29. Lv C, Hao Y and Tu G: MicroRNA-21 promotes proliferation, invasion and suppresses apoptosis in human osteosarcoma line MG63 through PTEN/Akt pathway. Tumour Biol 37: 9333-9342, 2016.

30. Ziyan W, Shuhua Y, Xiufang W and Xiaoyun L: MicroRNA-21 is involved in osteosarcoma cell invasion and migration. Med Oncol 28: 1469-1474, 2011.

31. Liu ZL, Wang H, Liu J and Wang ZX: MicroRNA-21 (miR-21) expression promotes growth, metastasis, and chemo- or radioresistance in non-small cell lung cancer cells by targeting PTEN. Mol Cell Biochem 372: 35-45, 2013.

32. Zhuang LK, Yang YT, Ma X, Han B, Wang ZS, Zhao QY, Wu LQ and Qu ZQ: MicroRNA-92b promotes hepatocellular carcinoma progression by targeting Smad7 and is mediated by long non-coding RNA XIST. Cell Death Dis 7: e2203, 2016.

33. Xu LF, Wu ZP, Chen Y, Zhu QS, Hamidi S and Navab R: MicroRNA-21 (miR-21) regulates cellular proliferation, invasion, migration, and apoptosis by targeting PTEN, RECK and Bcl-2 in lung squamous carcinoma, Gejiu City, China. PLoS One 9: e103698, 2014.

34. Guo H, German P, Bai S, Barnes S, Guo W, Qi X, Lou H, Liang J, Jonasch E, Mills GB, et al: The PI3K/AKT Pathway and Renal Cell Carcinoma. J Genet Genomics 42: 343-353, 2015.

35. Nakanishi A, Wada Y, Kitagishi Y and Matsuda S: Link between PI3K/AKT/PTEN Pathway and NOX Proteinin Diseases. Aging Dis 5: 203-211, 2014.

36. Wu YR, Qi HJ, Deng DF, Luo YY and Yang SL: MicroRNA-21 promotes cell proliferation, migration, and resistance to apoptosis through PTEN/PI3K/AKT signaling pathway in esophageal cancer. Tumour Biol 37: 12061-12070, 2016.

37. Tsunoda T, Ishikura S, Doi K, Matsuzaki H, Iwaihara Y and Shirasawa S: Resveratrol induces luminal apoptosis of human colorectal cancer HCT116 cells in three-dimensional culture. Anticancer Res 34: 4551-4555, 2014.

38. Fu Y, Chang H, Peng X, Bai Q, Yi L, Zhou Y, Zhu J and Mi M: Resveratrol inhibits breast cancer stem-like cells and induces autophagy via suppressing $\mathrm{Wnt} / \beta$-catenin signaling pathway. PLoS One 9: e102535, 2014. 
39. Larrosa M, Tomás-Barberán FA and Espín JC: The grape and wine polyphenol piceatannol is a potent inducer of apoptosis in human SK-Mel-28 melanoma cells. Eur J Nutr 43: 275-284, 2004

40. Liu WH and Chang LS: Suppression of Akt/Foxp3-mediated miR-183 expression blocks Sp1-mediated ADAM17 expression and $\mathrm{TNF} \alpha$-mediated $\mathrm{NF \kappa B}$ activation in piceatannol-treated human leukemia U937 cells. Biochem Pharmacol 84: 670-680, 2012.

41. Kang CH, Moon DO, Choi YH, Choi IW, Moon SK, Kim WJ and Kim GY: Piceatannol enhances TRAIL-induced apoptosis in human leukemia THP-1 cells through Sp1- and ERK-dependent DR5 up-regulation. Toxicol In Vitro 25: 605-612, 2011.

42. Lee RC, Feinbaum RL and Ambros V: The C. elegans heterochronic gene lin-4 encodes small RNAs with antisense complementarity to lin-14. Cell 75: 843-854, 1993.

43. Wu QB, Chen J, Zhu JW, Yin X, You HY, Lin YR and Zhu HQ MicroRNA 125 inhibits RKO colorectal cancer cell growth by targeting VEGF. Int J Mol Med 42: 665-673, 2018.

44. Zhang J, Yan YG, Wang C, Zhang SJ, Yu XH and Wang WJ: MicroRNAs in osteosarcoma. Clin Chim Acta 444: 9-17, 2015.

45. Kumar A, Rimando AM and Levenson AS: Resveratrol and pterostilbene as a microRNA-mediated chemopreventive and therapeutic strategy in prostate cancer. Ann N Y Acad Sci 1403 $15-26,2017$.

46. Ke K, Sul OJ, Rajasekaran M and Choi HS: MicroRNA-183 increases osteoclastogenesis by repressing heme oxygenase-1. Bone 81: 237-246, 2015.

47. Lu J, Song G, Tang Q, Yin J, Zou C, Zhao Z, Xie X, Xu H, Huang G, Wang J, et al: miR-26a inhibits stem cell-like phenotype and tumor growth of osteosarcoma by targeting Jagged1. Oncogene 36: 231-241, 2017.

48. Cheng D, Qiu X, Zhuang M, Zhu C, Zou H and Liu Z: MicroRNAs with prognostic significance in osteosarcoma: A systemic review and meta-analysis. Oncotarget 8: 81062-81074, 2017.

49. Song MS, Salmena L and Pandolfi PP: The functions and regulation of the PTEN tumour suppressor. Nat Rev Mol Cell Biol 13: 283-296, 2012

50. Butler MS, Robertson AAB and Cooper MA: Natural product and natural product derived drugs in clinical trials. Nat Prod Rep 31: 1612-1661, 2014
51. Pan M-H, Ghai G and Ho CT: Food bioactives, apoptosis, and cancer. Mol Nutr Food Res 52: 43-52, 2008.

52. Aravindaram K and Yang NS: Anti-inflammatory plant natural products for cancer therapy. Planta Med 76: 1103-1117, 2010.

53. Tosetti F, Noonan DM and Albini A: Metabolic regulation and redox activity as mechanisms for angioprevention by dietary phytochemicals. Int J Cancer 125: 1997-2003, 2009.

54. Shammas MA, Koley H, Batchu RB, Neri P, Tassone P, Prabhala R, Anderson KC and Munshi NC: Specific Killing of Multiple Myeloma Cancer Cells by Epigallocatechin-3-Gallate Extracted from Green Tea. Blood 104: 2461, 2004.

55. Kwon KH, Barve A, Yu S, Huang MT and Kong ANT: Cancer chemoprevention by phytochemicals: Potential molecular targets, biomarkers and animal models. Acta Pharmacol Sin 28: 1409-1421, 2007.

56. Singh RP, Tyagi A, Sharma G, Mohan S and Agarwal R: Oral silibinin inhibits in vivo human bladder tumor xenograft growth involving down-regulation of survivin. Clin Cancer Res 14: 300-308, 2008.

57. Ku KL, Chang PS, Cheng YC and Lien CY: Production of stilbenoids from the callus of Arachis hypogaea: A novel source of the anticancer compound piceatannol. J Agric Food Chem 53: 3877-3881, 2005

58. Chen XR, Lu R, Dan HX, Liao G, Zhou M, Li XY and Ji N: Honokiol: A promising small molecular weight natural agent for the growth inhibition of oral squamous cell carcinoma cells. Int J Oral Sci 3: 34-42, 2011.

59. Yang J,Zou Y and Jiang D: Honokiol suppresses proliferation and induces apoptosis via regulation of the miR 21/PTEN/PI3K/AKT signaling pathway in human osteosarcoma cells. Int J Mol Med 41: 1845-1854, 2018.

This work is licensed under a Creative Commons Attribution-NonCommercial-NoDerivatives 4.0 International (CC BY-NC-ND 4.0) License. 